
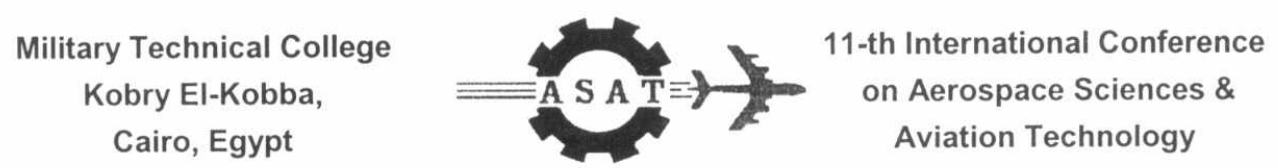

\title{
DESIGN AND ANALYSIS OF DYNAMIC PERFORMANCE OF A VEHICLE ACTIVE SUSPENSION SYSTEM
}

\author{
Z. A. IBRAHIM*I. A. ELSHERIF** M. G. RABIE*** S. A. HEGAZY****
}

\begin{abstract}
In this work, the design and analysis of a hydropneumatic slow active suspension with leveling system is developed. The design based on a hydropneumatic suspension unit with a shock absorber element of an existing car and an electrohydraulic servo valve.

A nonlinear mathematical model of a quarter car with active suspension system is deduced. The mathematical model considers the real dynamic behavior of the hydropneumatic suspension unit and the electrohydraulic servo valve.

The classical control theory is used to design the control system of the active suspension system, a proportional derivative controller (PD) is used for leveling system control and the proportional integral controller $(\mathrm{PI})$ is used for controlling and minimizing the vertical body acceleration due to the road irregularities.

Using the MATLAB tool kit, a simulation program for the designed system is developed. The main suspension disturbances, road irregularities, and the inertial forces are modeled and simulated. The tire is simulated by linear damper and linear spring. The simulation model is used to predict the dynamic response of vehicle body under different types of roads and dynamic loads. The simulation model is also used to compare the performance of the designed active system with the passive system.
\end{abstract}

\section{KEY WARDS}

Slow Active suspension - Electrohydraulic servovalve - Quarter car model Leveling system - passive suspension.

\footnotetext{
${ }^{*}$ M.Sc. Egyptian Armed Forces.

** Ph.D, Egyptian Armed Forces.

*** Prof., Egyptian Armed Forces.

${ }^{\star * \star *}$ Ph.D, Egyptian Armed Forces.
} 


\section{NOMENCLATURE}

$\mathrm{A}_{\mathrm{a}}$ Throttling area due to the movement of the spool of EHSV, $\mathrm{m}^{2}$.

$A_{p} \quad$ Piston area of the suspension unit, $\mathrm{m}^{2}$.

Ac Fixed damping orifice area in compression and rebound stroke, $\mathrm{m}^{2}$.

$A_{c 1}$ Variable damping orifice area in direction of compression stroke, $\mathrm{m}^{2}$.

$A_{c 2}$ Variable damping orifice area in direction of rebound stroke, $\mathrm{m}^{2}$.

$A_{s} \quad$ Spool cross-section area, $\mathrm{m}^{2}$.

Ar Spool radial clearance area, $m$.

b Orifice width, $m$.

B Oil Bulk modulus, $\mathrm{Pa}$.

C Radial clearance between the spool and the sleeve, $\mathrm{m}$.

$\mathrm{C}_{d} \quad$ Discharge coefficient.

$\mathrm{C}_{\mathrm{t}} \quad$ Damping coefficient of the tire, $\mathrm{Ns} / \mathrm{m}$.

$\mathrm{D}_{\mathrm{s}} \quad$ Spool diameter, $\mathrm{m}$.

$F_{j} \quad$ The flow force on the spool, $N$.

$F_{S} \quad$ The feedback spring force, $N$.

$\mathrm{i}_{\mathrm{e}} \quad$ Error current, $\mathrm{A}$

k Gain factor.

$\mathrm{K}_{\mathrm{t}} \quad$ Stiffness constant of tire, $\mathrm{N} / \mathrm{m}$.

$\mathrm{m}_{\mathrm{s}} \quad$ Sprung mass, $\mathrm{kg}$.

$\mathrm{m}_{\mathrm{us}} \quad$ Unsprung mass, $\mathrm{kg}$.

$\mathrm{P}_{1}$ Pressure in the LHS spool chamber, $\mathrm{N} / \mathrm{m}^{2}$.

$\mathrm{P}_{2}$ Pressure in the RHS spool chamber, $\mathrm{N} / \mathrm{m}^{2}$.

$P_{P} \quad$ Pressure in the piston chamber, $\mathrm{N} / \mathrm{m}^{2}$.

$P_{S}$ Supply pressure, $\mathrm{N} / \mathrm{m}^{2}$.

$Q_{a} \quad$ Flow rate through the orifice area $A_{a}, \mathrm{~m}^{3} / \mathrm{s}$.

$Q_{b} \quad$ Flow rate through the orifice area $A_{b}, \mathrm{~m}^{3} / \mathrm{s}$

$Q_{p} \quad$ Flow rate through the damping orifices of the shock absorber, $\mathrm{m}^{3} / \mathrm{s}$.

S Lablace operator.

$V_{N}$ Volume of nitrogen, $\mathrm{m}^{3}$.

$V_{p} \quad$ Volume of oil in piston chamber, $\mathrm{m}^{3}$

x Spool displacement of the electrohydraulic servovalve, $m$.

$x_{r} \quad$ Displacement of the spool with representative model, $m$.

$\mathrm{x}_{\mathrm{s}} \quad$ Displacement of the spool with validated model, $\mathrm{m}$.

$z_{0} \quad$ Road input displacement, $m$.

$z_{1} \quad$ Vehicle body displacement, $m$.

$\mathrm{z}_{2} \quad$ Wheel assembly displacement, $\mathrm{m}$.

$\omega_{n} \quad$ Natural frequency of the EHSV, $\mathrm{Hz}$.

$\xi \quad$ Damping coefficient.

\section{ABBREVIATIONS}

EHSV Electrohydraulic servovalve.

LVDT Linear variable differential transformer.

RHS Right hand side

LHS Left hand side

TF Transfer function 


\section{Introduction}

The primary functions of the suspension system are to minimize the vertical acceleration of the vehicle body to increase the passenger comfort, to minimize the dynamic tire load variations, to provide maximum road holding capability during cornering and braking, and to react to load changes on the vehicle body that occur during maneuvering and when the passenger load changes.

The vehicle suspension design has to compromise between the passenger comfort and the improvement of handling characteristics of the vehicle [1-5]. The usage of active elements in the suspension eliminates part of this compromise by changing the suspension characteristics. However, limitations of the passive suspension design still exist due to the finite suspension travel and invariant points in the suspension transfer function [6].

To overcome some of the mentioned limitations of the passive suspensions design, active suspension is introduced to enhance these conflicting requirements of the passive suspensions [7-10]. In this paper, the design and analysis of a slow active hydropneumatic suspension with leveling system are developed and studied.

\section{Description of the Designed Active Suspension System.}

The electrohydraulic servo system is used in the design of the proposed active suspension system. The designed system shown in Fig.1 composes of the following components, a pump, pressure relief valve, hydraulic accumulator, electrohydraulic servovalve (EHSV), linear variable differential transformer (LVDT) built in with the hydraulic cylinder, accelerometer attached to the sprung mass, two controllers and hydropneumatic suspension unit with damping element (shock absorber).

\section{Mathematical Model of The Active Suspension System}

To simplify the modeling of the designed active suspension, the following assumptions have been considered:

a- The pump load pressure is smaller than the preset relief pressure of the relief valve, hence the relief valve is excluded from the mathematical model.

b- The sprung and unsprung mass move upward, and the hydropneumatic suspension unit is in the compression mode.

c- The transmission lines, being of very short length, are of negligible effect.

d- Oil properties such as density, viscosity and bulk modulus are assumed constant.

e- The coefficient of discharge is assumed constant.

$\mathrm{f}$-The supply pressure is nearly constant.

\subsection{Mathematical Model of The Electrohydraulic Servovalve}

\subsubsection{Mathematical model of the first stage.}

The simulation program of the validated mathematical model of the first stage of the two stage electrohydraulic servovalve incorporating a jet pipe amplifier [11] is used to calculate the step response of the spool displacement of EHSV due to the step input 
current of $10 \mathrm{~mA}$. It is found that the step response of the spool displacement behaves like an over damped second order system, which can be described by the following transfer function of the second order system.

$$
G(s)=\frac{x}{i_{e}}(s)=\frac{k}{\left(\frac{1}{\omega_{n}^{2}}\right) s^{2}+\left(\frac{2 \xi}{\omega_{n}}\right) s+1}
$$

The coefficients of the corresponding representative transfer function for the first stage of the EHSV $k, \omega_{n}$ and $\xi$ are calculated. It is found that the gain factor $k=0.027983$, natural frequency of the EHSV is $\omega_{n}=400 \mathrm{rad} / \mathrm{sec}$ or $66 \mathrm{~Hz}$ and the damping ratio is $\xi=0.99$. Then the representative transfer function is:

$$
\mathrm{G}(\mathrm{s})=\frac{\mathrm{x}}{\mathrm{i}_{\mathrm{e}}}=\frac{0.027983}{6.3 \mathrm{E}-6 \mathrm{~s}^{2}+0.00495 \mathrm{~s}+1}
$$

The Integral of error squared is calculated as follows:

$$
\mathrm{IES}=\int_{0}^{\infty}\{\mathrm{e}(\mathrm{t})\}^{2} \mathrm{dt}
$$

Where $e(t)=\int\left(x_{r}-x_{s}\right)^{2} d t$

It is found that the error has very small value, IES $=6 \times 10^{-11}$, as shown in Fig. 2 . This gives a confidence to use the representative transfer function to describe the relation between the input current to the EHSV and the displacement of its spool in the simulation of the proposed active suspension system.

\subsubsection{Mathematical model of second stage of servo valve}

The second stage of servo valve consists of a spool and a sleeve with rectangular slots, as shown in Fig. 3. The motion of the spool could be described by the following equation.

$$
A_{s}\left(P_{2}-P_{1}\right)=m_{s} \frac{d^{2} x}{d t^{2}}+f_{s} \frac{d x}{d t}+F_{j}+F_{s}
$$

Neglecting the effect of the flow forces [12] and the effect of the inner hydraulic transmission lines. The flow rates through the zero-lapping valve restriction area, Fig. 4, are given by:

$$
\begin{aligned}
& Q_{a}=C_{d} A_{a}(x) \sqrt{\frac{2}{\rho}\left(P_{s}-P_{P}\right)} \\
& Q_{b}=C_{d} A_{b}(x) \sqrt{\frac{2}{\rho}\left(P_{P}-P_{t}\right)}
\end{aligned}
$$


Where,

$$
\begin{aligned}
& \left.\begin{array}{l}
A_{a}(x)=A_{r} \\
A_{b}(x)=2 b x+A_{r}
\end{array}\right] \quad \text { for }(x \geq 0) \\
& \left.\begin{array}{l}
A_{b}(x)=A_{r} \\
A_{a}(x)=2 b x+A_{r}
\end{array}\right] \text { for }(x<0) \\
& A_{r}=\pi\left(D_{s}+c\right) c
\end{aligned}
$$

\subsection{Mathematical Model of Hydropneumatic Suspension Unit.}

The developed and validated mathematical model [13] of the hydropneumatic suspension unit is used in mathematical modeling and simulation of the designed active suspension system.

The continuity of flow in the hydraulic cylinder due to the connection with the EHSV is deduced by the following equation, Fig. 4.

$$
Q_{a}-Q_{b}-Q_{p}+A_{p}\left(\frac{d z_{2}}{d t}-\frac{d z_{1}}{d t}\right)=\frac{V_{P}-A_{P}\left(z_{2}-z_{1}\right)}{B} \frac{d P_{P}}{d t}
$$

\subsection{Mathematical Description of Quarter-car Model}

The developed mathematical model of the quarter-car is used in modeling of the active suspension, Fig. 4.

Equation of motion of the vehicle body (sprung mass),

$$
P_{P} A_{P}-M_{S} g-f_{P}\left(\frac{d z_{1}}{d t}-\frac{d z_{2}}{d t}\right)=M_{S} \frac{d^{2} z_{1}}{d t^{2}}
$$

Equation of motion of the wheel assembly (un-sprung mass),

$$
K_{t}\left(z_{2}-z_{o}\right)+C_{t}\left(\frac{d z_{2}}{d t}-\frac{d z_{o}}{d t}\right)-M_{u S} g-P_{p} A_{p}-f_{p}\left(\frac{d z_{2}}{d t}-\frac{d z_{1}}{d t}\right)=M_{U S} \frac{d^{2} z_{2}}{d t^{2}}
$$

\section{Design of Active Suspension Control System.}

\subsection{Design of Leveling System Controller.}

In order to decrease the settling time of the leveling system due to over shoot in the vehicle body motion, a derivative element is used in addition to the proportional feedback element, Fig.5, Ziegler-Nichols rule [14]. The transfer function of the proportional derivative controller (PD) for the leveling system is $(30+8 s)$.

In studying of the leveling system performance, the vehicle body is subjected to vertical step load with the value $800 \mathrm{~N}$. After the refine tuning of the calculated parameters of the PD controller, the response of the leveling system is obtained, Fig.6. The vehicle body reaches the steady state position in less than 2.3 second without any oscillations. This improves the sensation of comfortability for passengers, 
and proves the capability of the designed system to remove any static and dynamic load variations in the vehicle body. The vehicle body dose not return to the initial position due to the increase of the tire deflection after the step load. The deflection of the suspension system does not exceed $0.033 \mathrm{~m}$.

Comparison of Fig. 7 with Fig. 6 shows the corresponding suspension deflection. It is noticed that, there is a positive overshoot in the suspension deflection at the instance of application of the step load. This is due to the increase of the suspension rattle space. The behavior of the suspension can be explained as follows, after the new loading conditions, the cylinder pressure is increased, therefore, the vehicle body starts to move upward increasing the suspension deflection, but the EHSA system returns the suspension deflection to the initial position in 2.3 seconds.

Present design of slow active suspension with leveling system improves the performance of the leveling system in comparison with El-Demerdash and Crolla design [15]. In present design the EHSV is used instead of electrohydraulic proportional control valve. The design using the EHSV decreases the time needed to the vehicle body to reach the steady state value of 2.3 seconds, while the other design takes 30 seconds under the same dynamic load application to reach the steady state.

\subsection{Design of Ride Controller.}

In the acceleration control loop, the integral element is added to the proportional element. The transfer function of the PI controller is chosen according to ZieglerNichols rule to be $D(s)=3+6 / s$. The $P$ I controller is used to control the vehicle body acceleration, Fig.8. From the experience of simulation program, it is found that the two terms of the controller have a great effect on suspension performance. The proportional element has a large effect on minimizing the vehicle body acceleration and the integral term has a great effect on the suspension damping. The control loop achieves the required specification of the active suspension. Although the step input from the road is $50 \mathrm{~mm}$, the over shoot of the vehicle body displacement does not exceed $3 \mathrm{~mm}$, as shown in Fig. 9-

\section{Simulation of Active Suspension System}

The mathematical model of the quarter car model incorporating the electrohydraulic servovalve and the hydropneumatic suspension unit is simulated using the SIMULINK program of the MATLAP6.5 tool kit. The mathematical model is validated in two steps. First step, the mathematical model of the hydropneumatic suspension unit with the shock absorber is developed and validated. The validation is done by the comparison between the theoretical and experimental results, which showed a good agreement between them [13]. The second step is using the validated mathematical model of the first stage of the electrohydraulic servovalve [11] and calculating the equivalent transfer function, which describes nearly the exact dynamic behavior of the first stage of the servo valve. The second stage of the EHSV is described mathematically by applying the direct measurement to the throttling areas. These steps gives the confidence to use the simulation program which based on these non-linear mathematical models to investigate the dynamic behavior of the vehicle body due to real road profile. This road profile is considered as a random 
signal for studying the designed control system. The flowchart of the simulation program is shown in fig. 10 .

\section{Dynamic Response of the Vehicle With Active Suspension}

The dynamic response of the vehicle body due to the random, step, and sine road inputs is obtained theoretically. The random road input simulates the real road profile to obtain the dynamic response of the vehicle. The step input displacement is used for the purpose of the measurement of the ride passengers comfortability with passive suspension and with active suspension systems. In evaluation of dynamic response of the vehicle, the three main aspects of the suspension system are used; the vehicle body acceleration, the dynamic tire load and the suspension working space. The effect of different shapes of disturbances from the road in the main aspects is studied to evaluate the dynamic response of the vehicle body with the active suspension system.

\subsection{Dynamic Response Due to Random Road Input Displacement}

The dynamic response of the vehicle body acceleration due to the random road input is shown in Fig.11. It is noticed that the vehicle body acceleration with active suspension is lowered by about $48 \%$ from the vehicle body acceleration with passive suspension. This means that the active suspension is capable of achieving better ride characteristics by decreasing the body acceleration in comparison with the passive suspension.

The dynamic response of the vehicle body displacement is shown in Fig.12. It is noticed that, the vehicle body displacement of active suspension is less than the vehicle body displacement of passive suspension. Consequently, the oscillations of vehicle body in case of using active suspension is less than the oscillations of vehicle body in case of using passive suspension. This means that the ride characteristics are improved with the active suspension.

\subsection{Dynamic Response Due to Step Road Input Displacement}

The step road input is used to measure to what extent the active suspension is succeed to achieve better dynamic response for the vehicle body. This is done by comparison between the results due to subjecting the vehicle body with passive or active suspension to a step input equal to $0.05 \mathrm{~m}$ from the road, while the rate of change of vertical displacement of the road is, $1 \mathrm{~m} / \mathrm{s}$. The comparison is done especially at the peaks of the response in which the step input is applied.

Fig.13 shows the step response of the vehicle body acceleration due to a step road input. It is noticed that the vehicle body acceleration is decreased by $54 \%$ when using the active suspension at the moment of applying the input step, while the vehicle body acceleration is almost zero after that, which provide the maximum comfort ability required for passengers.

Fig.14 shows the dynamic response of the vehicle body displacement due to a step road input. It is noticed that with the use of active suspension system, there is only one body oscillation in the instance of application of the step road input. The maximum over shoot is decreased by $81.4 \%$ in comparison of the maximum over 
shoot happened with the use of passive suspension. This means that the active suspension achieves better damping in comparison with passive suspension, and decreases the vehicle body displacement to the lowest value at the same excitation source.

Fig.15 shows the dynamic tire load variations in passive and active suspensions, it is noticed that the active suspension decreases the peak value of the dynamic tire load by $1.5 \%$ at the instance of application of the step input from the road. The active suspension causes a more fluctuation in the transient period than the passive suspension. The rapid changes in dynamic tire load affects the acceleration, the braking and consequently the safety of vehicle.

Fig.16 shows the variation of the suspension working space due to the step input from the road. The suspension working space is defined as the distance between the displacement of the vehicle body and the wheel assembly. It is noticed that the suspension working space is decreased by $9 \%$ due to the exploitation of the active suspension system. The deflection of the suspension is increased in the instant of application of the step input from the road. This is happen due to connecting the cylinder chamber to the tank during the compression stroke. This action decreases the resistance in front of the motion of the wheel assembly, which allows it to go farther than the passive suspension without affecting the vehicle body. This reaction decreases the force transmitted to the vehicle body and consequently decreases the vehicle body motion. In this manner the active suspension reaches the steady state position within one oscillation, meanwhile the passive suspension reaches the final position after three oscillations through longer time than the active suspension.

\section{CONCLUSIONS}

An active hydropneumatic vehicle suspension with leveling system is designed. The design is based on commercially available hydropneumatic suspension unit for a passenger car and electrohydraulic servovalve. The hydropneumatic suspension unit is described by a non-linear mathematical model and the basic system nonlinearities are taken into consideration. The numerical values of constructional parameters are obtained by direct measurements on the real elements. A simulation program is developed for the hydropneumatic suspension unit. The dynamic behavior of this unit is predicted by using the simulation program. The transient response of the hydropneumatic suspension unit is evaluated experimentally. The comparison of simulation and experimental results shows a good agreement between them, which validates the simulation program.

The proposed active suspension system includes two-stage electrohydraulic servovalve incorporating a jet pipe amplifier. The transient response of the spool is introduced in the model by using of a second order transfer function. This transfer function is deduced by using a validated detailed model of the electrohydraulic servovalve. The other components of the proposed suspension system are described by nonlinear mathematical models. 
The implementation of PI, PD and PID controllers in the control loops is studied. The complete process of implementation, determination of control parameters and evaluation of response improvement is carried out. As a result, the implementation of $\mathrm{PD}$ controller in the leveling system and PI controller in the acceleration control give satisfactory results.

The simulation program is developed for a quarter car model, based on the deduced nonlinear mathematical relations. The program is created by using the SIMULINK package. The simulation program is used to predict the dynamic behavior of the vehicle. Different forms of suspension disturbance sources, road irregularities, and inertial forces, are considered during modeling and simulation.

The study showed that the active suspension achieves better characteristics when compared with the passive suspension, as follows:

- The vehicle body acceleration is decreased by $54 \%$.

- The vehicle body displacement is decreased by $81.4 \%$.

- The suspension working space is decreased by $9 \%$.

- The dynamic tire load is decreased by $1.5 \%$, but gives a very rapid fluctuation of its value for a very short time in the transient response. This fluctuation has bad effect on braking and acceleration performance of the vehicle.

The settling time of the quarter car model leveling system, in response to the step load increase, is found to be less than 2.3 seconds with the PD controller. This response is much faster than that obtained for systems using electrohydraulic proportional valves. This quick response gives an advantage for the designed system. It removes to some extent, the vehicle body roll and pitch motions during the steering and braking of the vehicle.

The experimentation on the simulation program proved that the tuning of parameters of the $\mathrm{PI}$ controller, used to control the vehicle body acceleration, has a great effect on the performance of active suspension. The increase of the integral element coefficient increases the damping in the suspension system, while the increase of the proportional element coefficient value decreases the vertical body acceleration.

\section{REFERENCES}

[1] D. A. Crolla, G. Firth, D. Horton, An Introduction to Vehicle Dynamics, Lecture notes, Department of Mechanical Engineering, University of Leads, 1994.

[2] A. W. Burton, A. J. Truscott, P. E. Wellstead, Analysis Modeling and control of an advanced automotive self leveling suspension system, I.E. proc. Control theory Application. Vol. 142, No. 2, March 1995.

[3] SUTTON, H. P. The potential of active uspension systems, Inst. Mechanical Engs, Automotive engineering, 193, pp. 21-24, 1979

[4] GOODHALL, R.L., and KORTUM, W., Active controls in ground transportation, Veh. Sys. Dyn., 12 ,pp. 225-257,1983

[5] HOGG, A.S, YARDLEY, A.G. MADDISON, S.J.RYANJP, Proc. of Mech.E. Vehicle ride and handling conference, pp .25-33.1993. 
[6] Wilson D A, Sharp R S, Hassan S A, The application of linear optimal control theory to the design of active suspensions, Vehicle System Dynamics,Vol. 15, 1986

[7] C. Pilbam, R.S. Sharp, performance potential and power consumption of slow active suspension system with preview, Vehicle system dynamics, 25, pp.196$183,1996$.

[8] A. Mansour Abdel-Haleem And D. Crolla, SAE, No. 2000-01-1631, 2000.

[9] Ali M. Abd EL-Tawaab,' Advanced Hydropneumatic Semi-Active suspension system Journal of low frequency noise, Vibration and active control, Vol. 20, No. 2, pp. 93-103, 2001.

[10] J. Watton, K. M. Holford and P. Surawattanawan, The application of a programmable servo controller to state control of an electrohydraulic active suspension, Proc. Instn. Mech. Engrs, Vol. 218 Part D, J. of automobile engineering, 2004.

[11] Ahmed Abd El-badia,An Investigation of the Dynamic Behavior of a Helicopter Electrohydraulic servo-Actuator, M.Sc. thesis, Zagazig University, 2002.

[12] Prof. M. Galal Rabie, Aircraft hydraulic and pneumatic systems, part 1, 2003.

[13] Z. A. Ibraheem, M. G. Rabie, A. Hegazy, I. A. Elsherif, The design and analysis of vehicle active suspension system, Ph.D. research.

[14] Gene F Franklin, J. David Powell, Abbas Emami-Naeini, Feedback control of dynamic systems, $3^{\text {rd }}$ Edition, Addison- Wesley publishing company Inc., 1994.

[15] S. M. EL - Demerdash, D.A. Corola, Effect of nonlinear components on the performance of a hydropneumatic slow active suspension system, Proc. Instn. Mech. Engrs, Vol. 210, 1996.

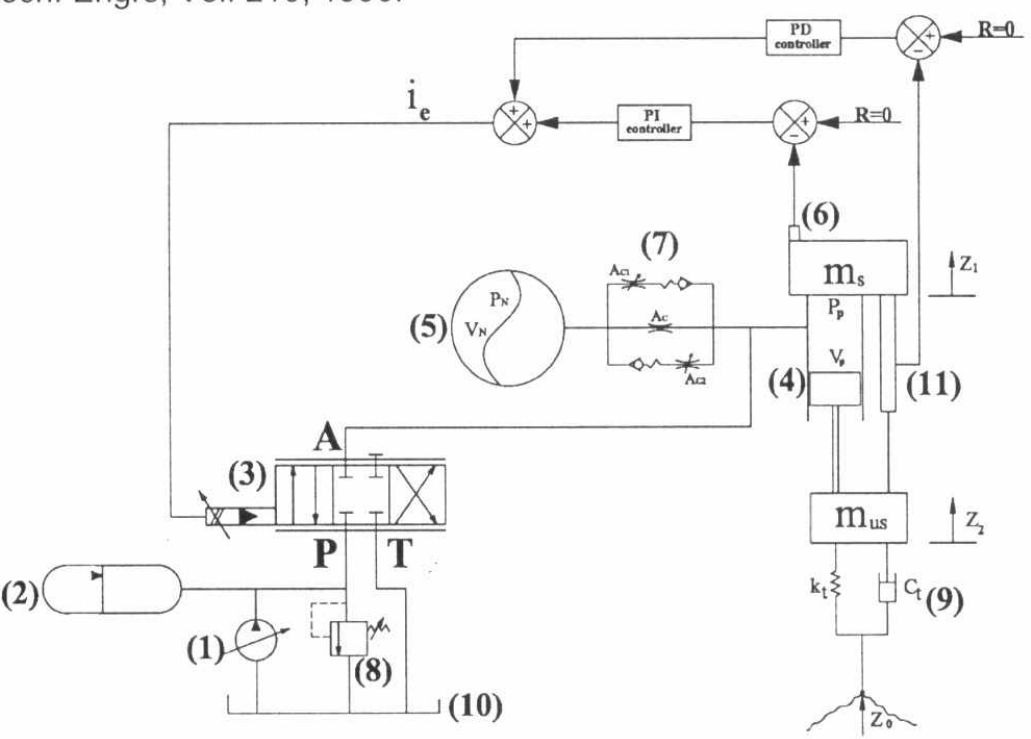

(1)Hydraulic pump, (2)Accumulator, (3)EHSV, (4)Hydraulic actuator, (5)Gas spring, (6) Accelerometer, (7)Throttle valve (damper), (8)Relief valve, (9)Tyre(spring +damper),

(10) Tank, (11) LVDT (displacement transducer)

Fig. 1 Schematic diagram of the designed active suspension system. 


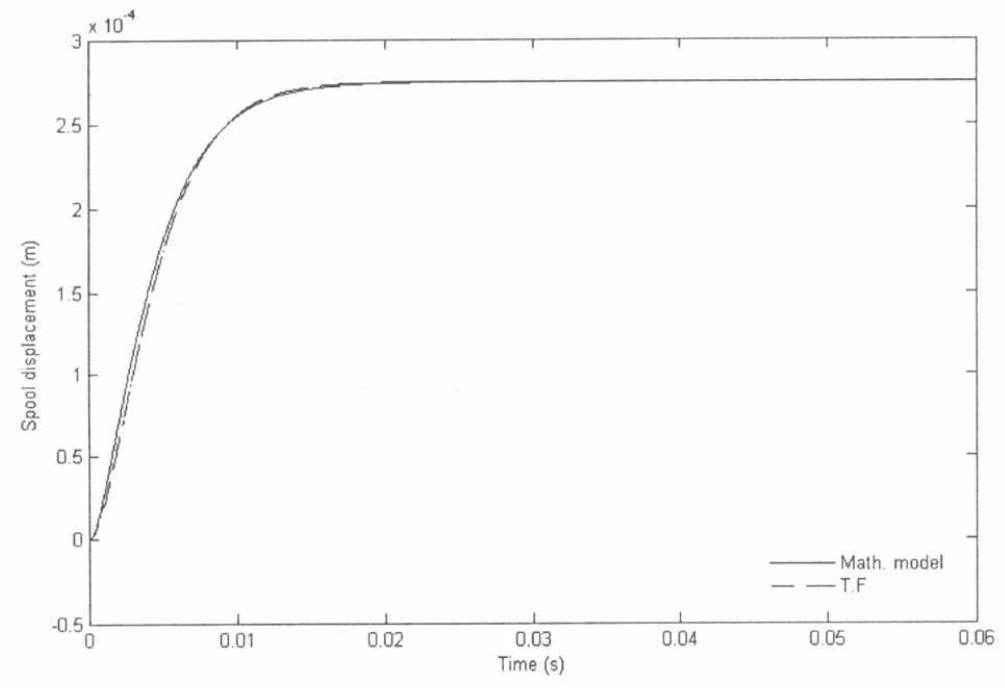

Fig. 2 Comparison between the step response of the spool displacement with using the validated mathematical model [11] and the representative transfer function.

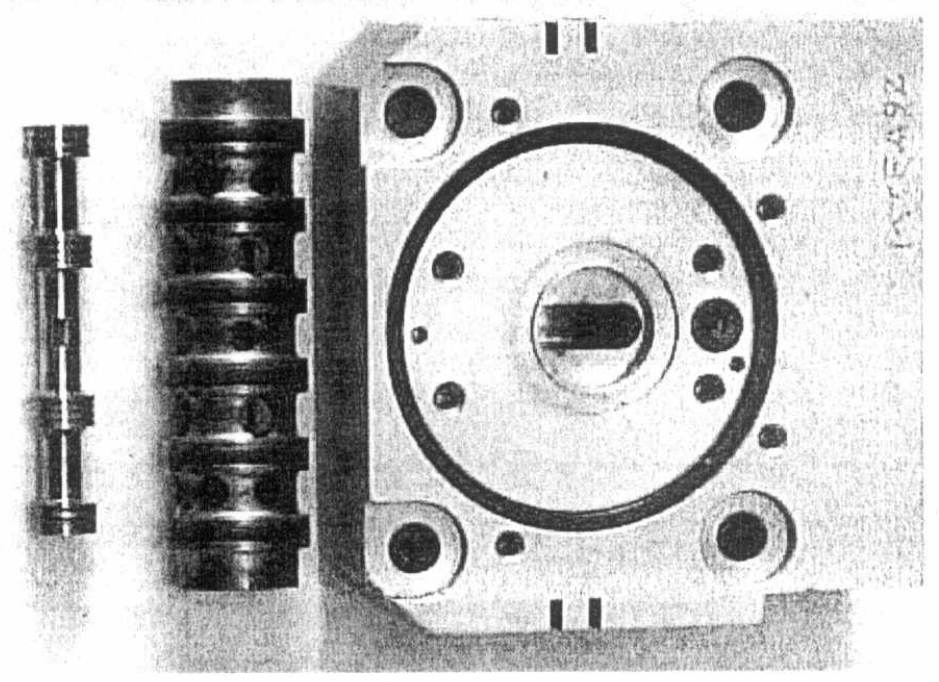

Fig. 3 Photo of spool and the sleeve with rectangular slots of the second stage of the studied jet pipe EHSV. 


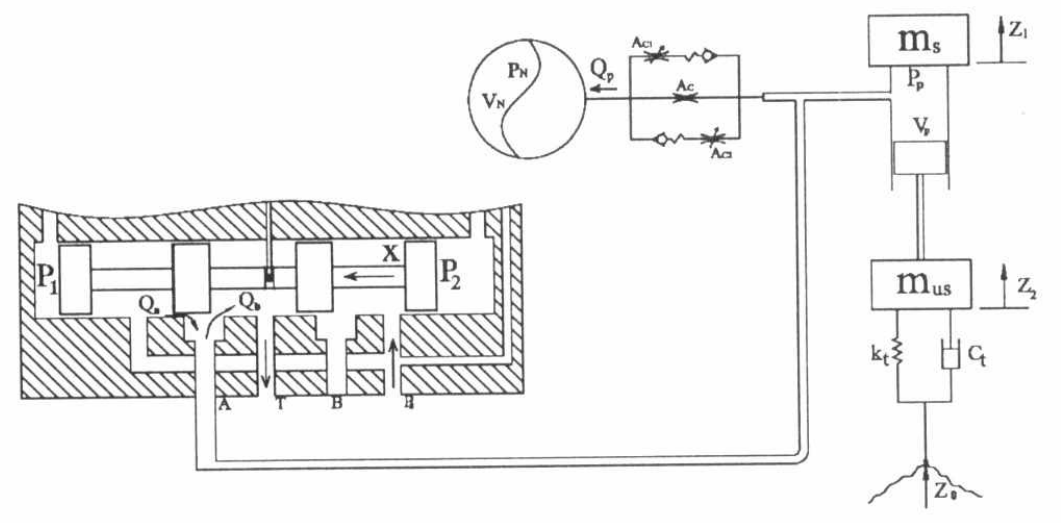

Fig. 4 Functional scheme of the simulated system components.

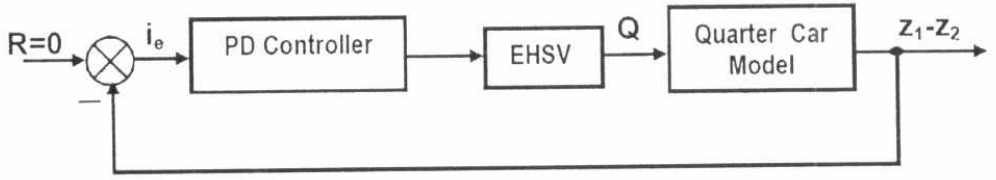

Fig. 5 Block diagram of the control system for vehicle body leveling

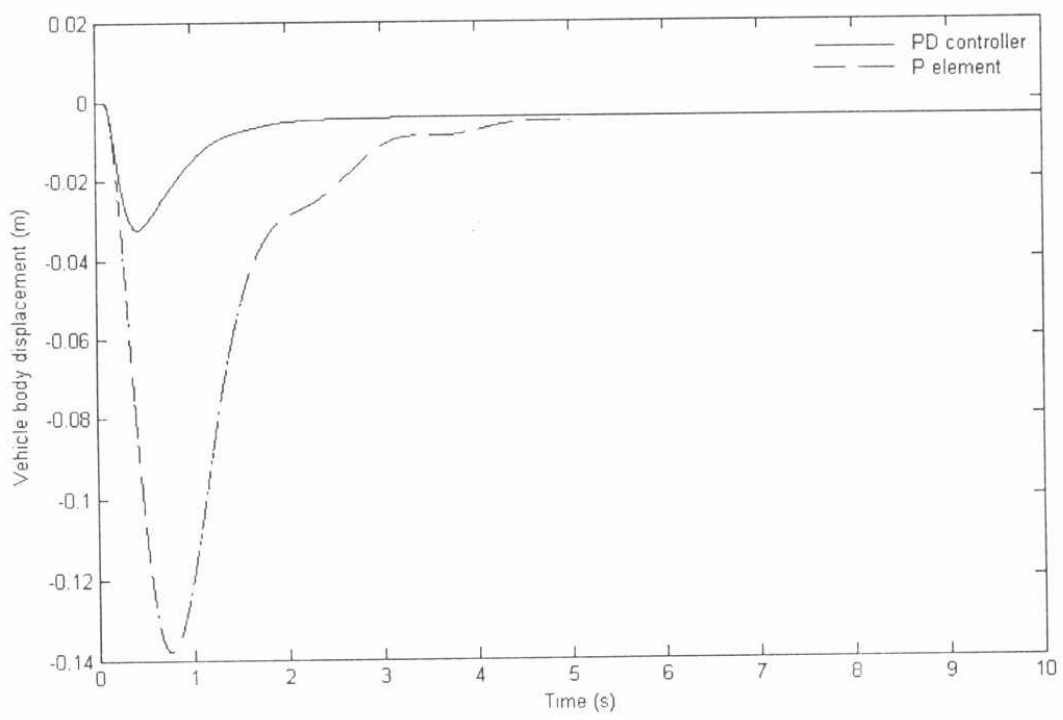

Fig. 6 Dynamic response of the vehicle body displacement due to step load $800 \mathrm{~N}$ with and without PD controller. 


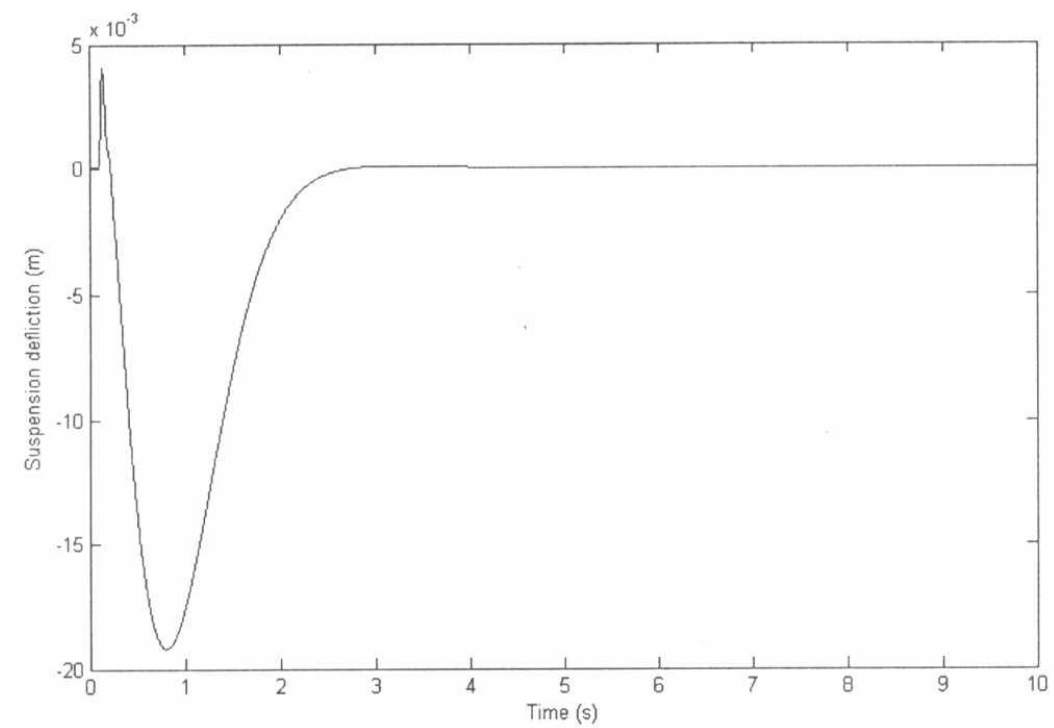

Fig.7 Dynamic responses of the suspension deflection due to step load $800 \mathrm{~N}$ with the use of PD controller.

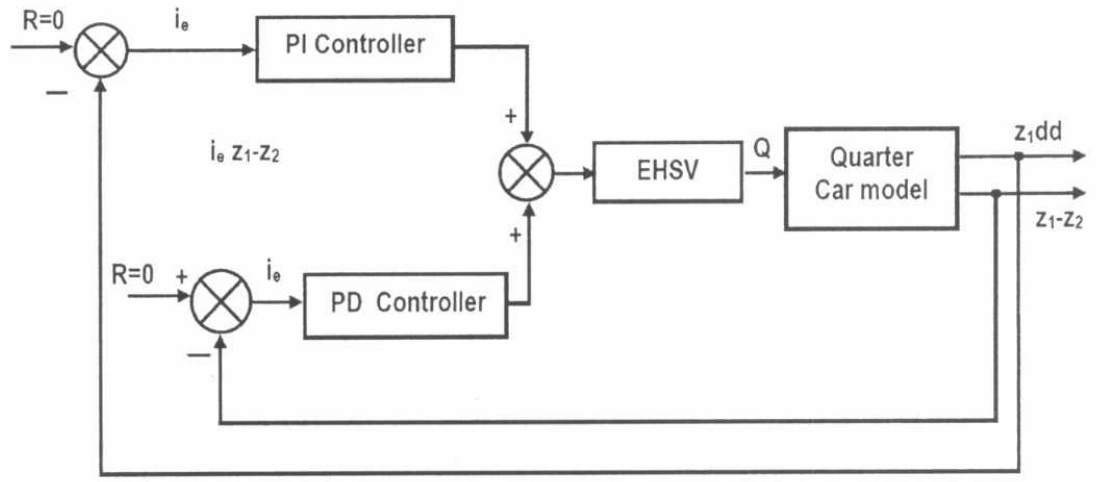

Fig. 8 Scheme of the final structure of the control system for the designed active suspension system. 


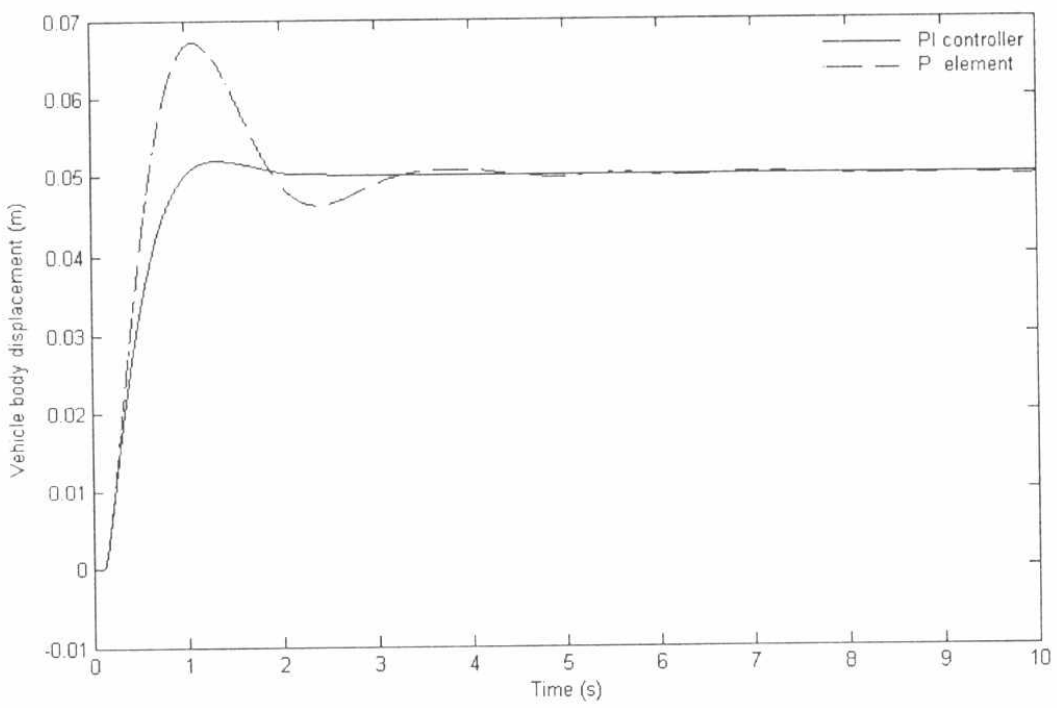

Fig.9 Dynamic response of vehicle body due to $0.05 \mathrm{~m}$ step input from the road.

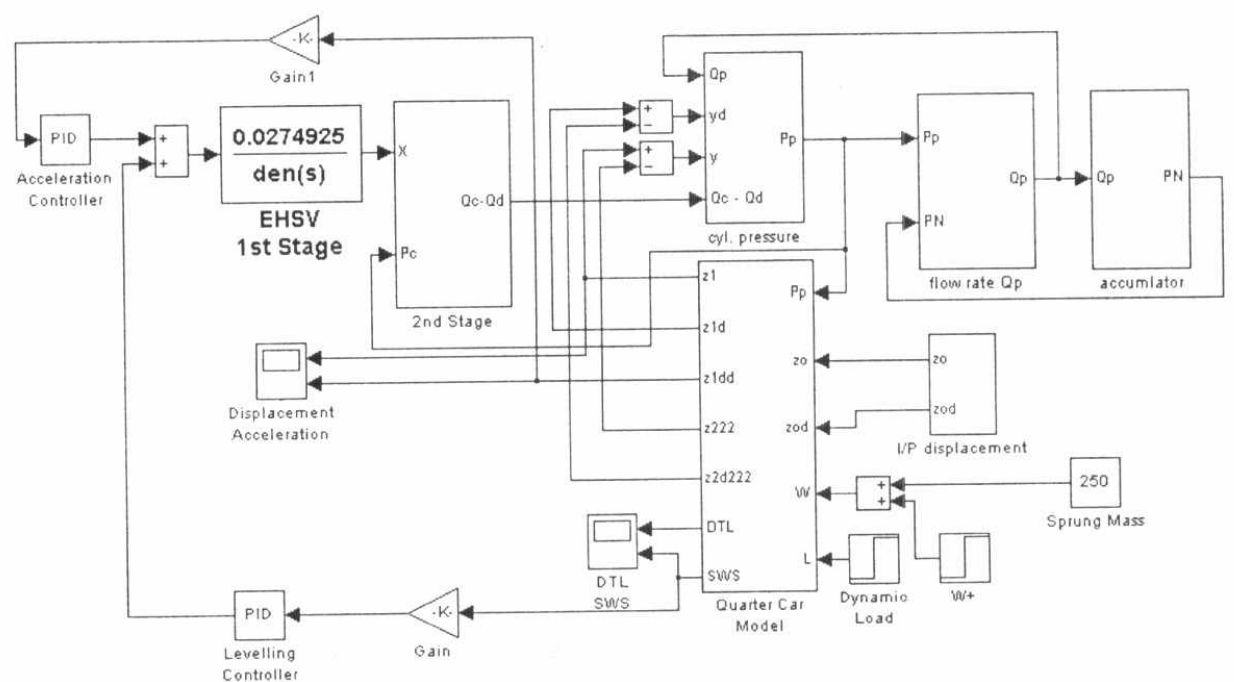

Fig.10 Flowchart of the simulation program of the quarter car model with active suspension system. 


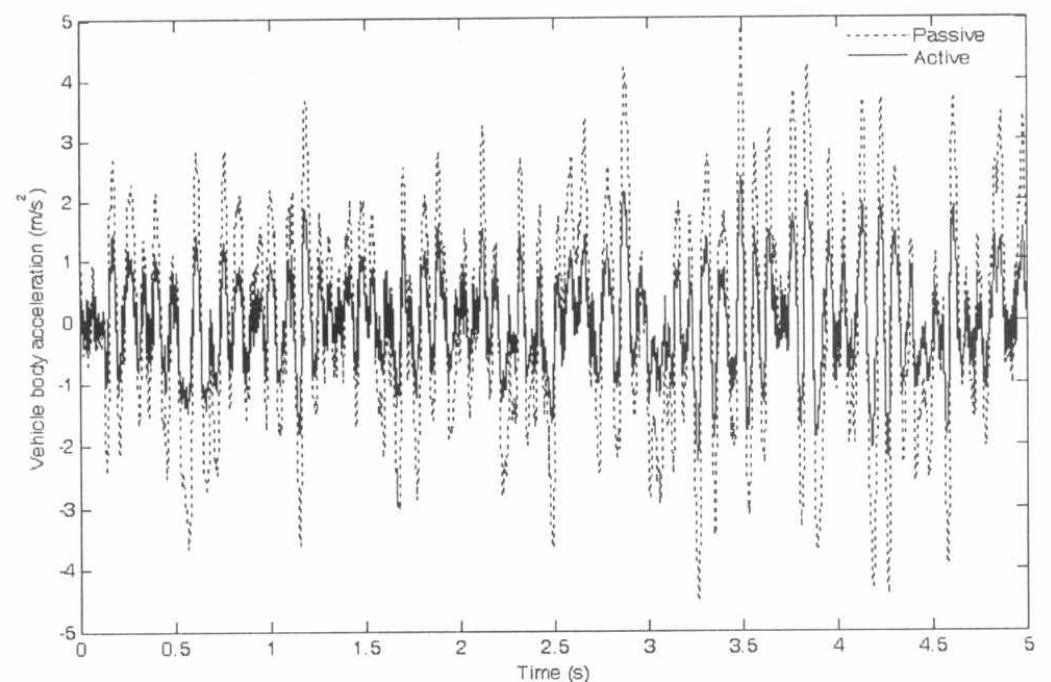

Fig.11 Dynamic response of the vehicle body acceleration due to random road input displacement.

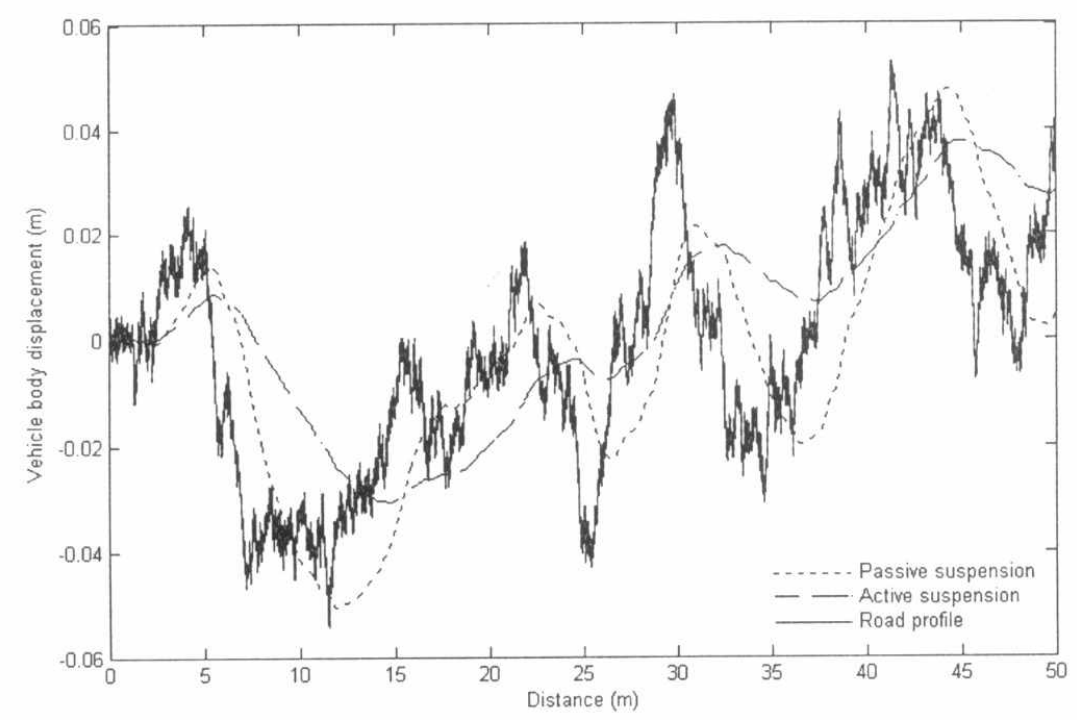

Fig.12 Dynamic response of vehicle body displacement due to random road input displacement. 


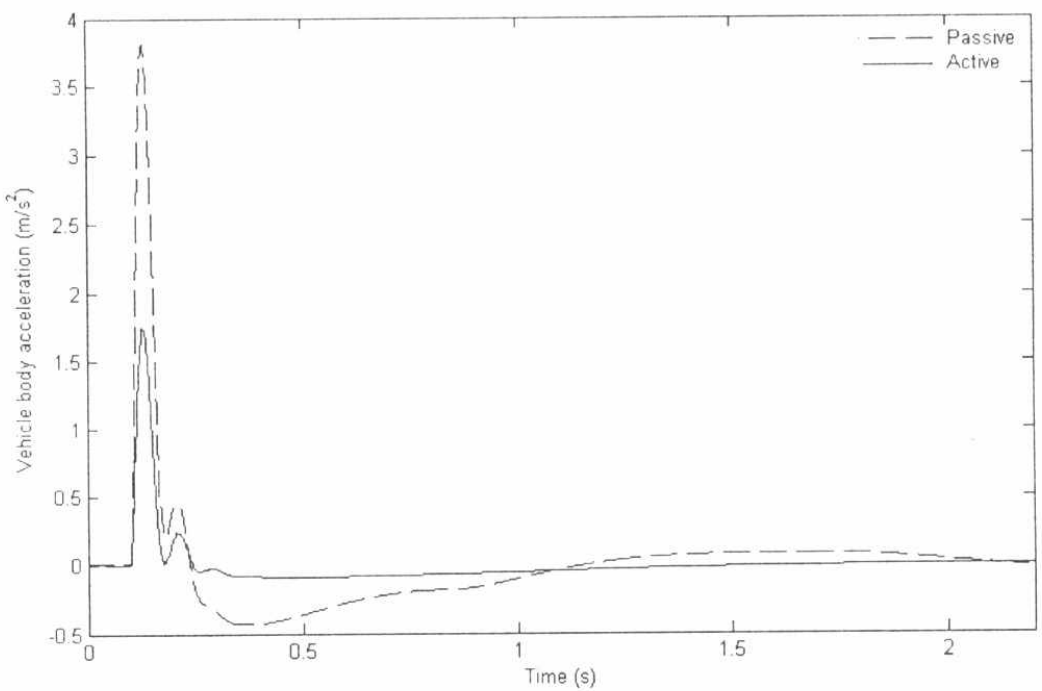

Fig.13 Step response of the vehicle body acceleration due to step road input with $0.05 \mathrm{~m}$ in passive and active suspensions.

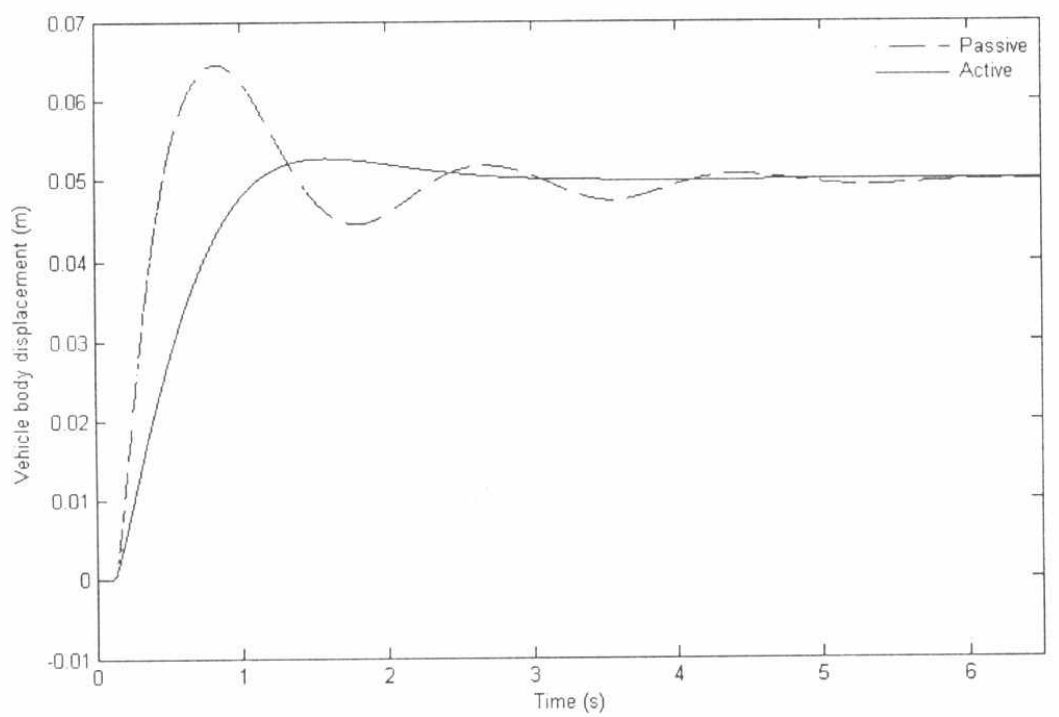

Fig. 14 Dynamic response of the vehicle body displacement due to step road input $0.05 \mathrm{~m}$ in passive and active suspensions. 


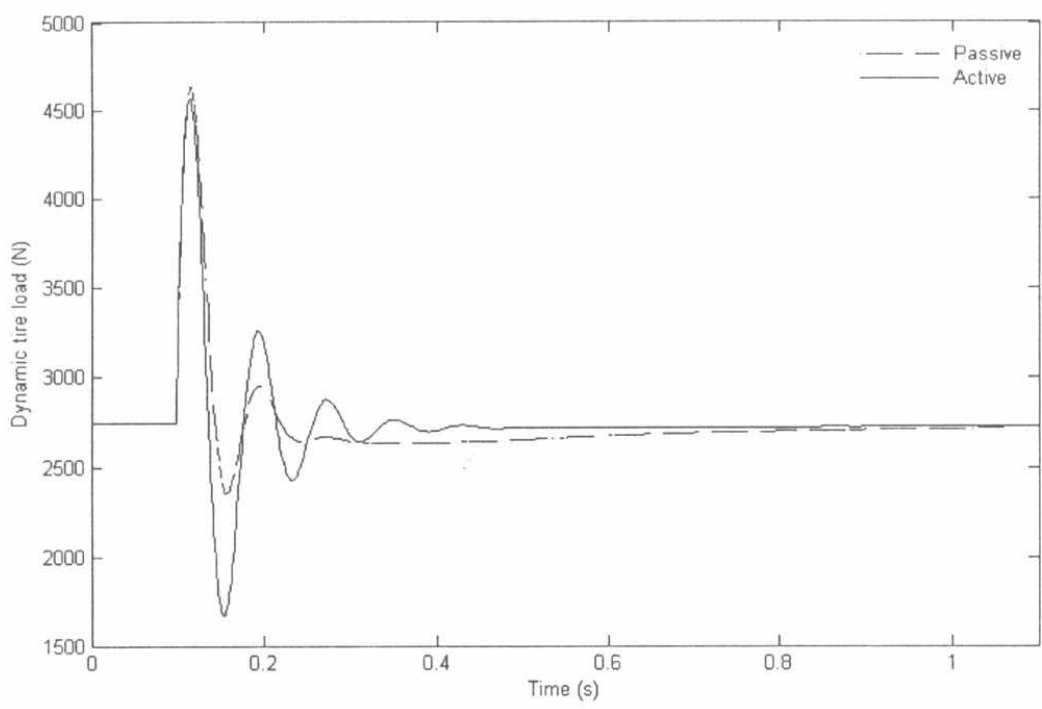

Fig. 15 Variation of the dynamic tire load due to step road input $0.05 \mathrm{~m}$ in passive and active suspensions.

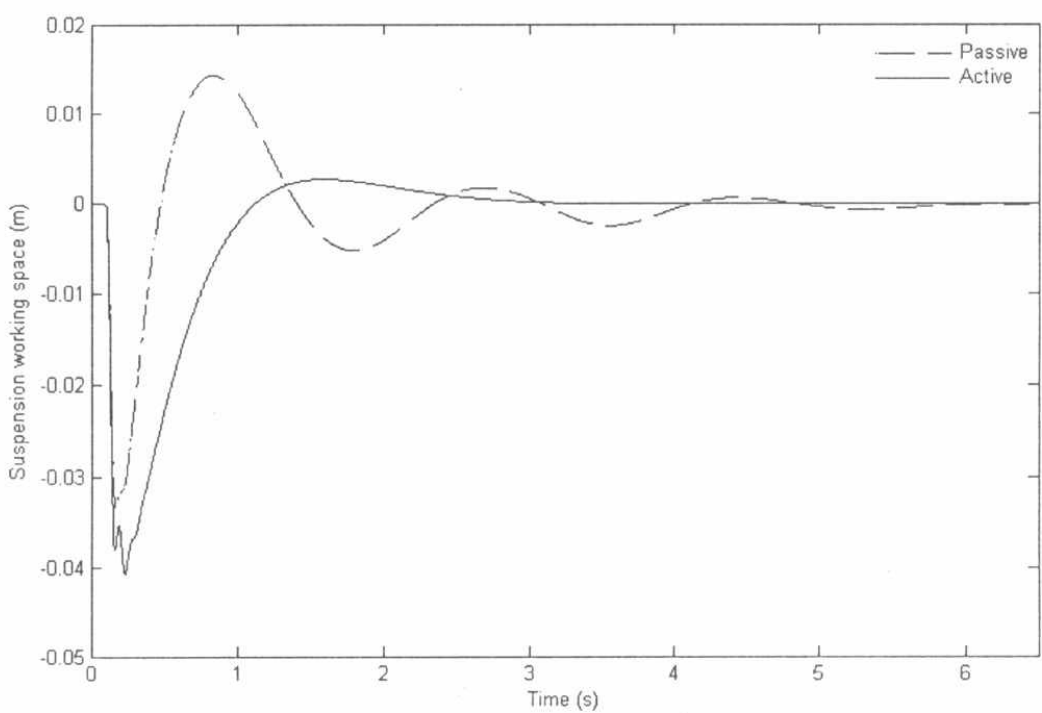

Fig.16 Variation of the suspension working space due to step road input $0.05 \mathrm{~m}$ in passive and active suspensions. 